\title{
LOS USOS DE LA CULTURA Y LA IDENTIDAD DESDE LA EXTENSIÓN UNIVERSITARIA EN ESTADOS UNIDOS
}

Claudia Matus* 


\section{RESUMEN}

El artículo cuestiona los usos de los conceptos de "cultura" e "identidad" en el contexto de los programas de extensión de la Universidad de Illinois en Estados Unidos. Para este caso, se han considerado los programas de ayuda que benefician a comunidades minoritarias y, más específicamente, la comunidad latina. Se plantean dos posturas y las consecuencias de cada una de ellas. En la primera, se hace alusión a una conceptualización más estática y unificada de las nociones de cultura e identidad, donde los sujetos son entendidos como parte de un origen ancestral. En la segunda, se plantea que se deben considerar las dinámicas producidas por la globalización y cómo este contexto permite una comprensión más desmitificadora de los conceptos en cuestión. Desde aquí se puede repensar la actividad de extensión universitaria como un espacio de articulación de diversas y múltiples narrativas.

\section{ABSTRACT}

The paper challenges the abuse of the concepts of "culture" and "identity" in the context of outreach programs at the University of Illinois, U.S.A. In this particular case, programs intended to benefit minority groups and-more specifically-the Hispanic community, were studied. The article proposes two approaches and describes the consequences of each. The first alludes to a more static conceptualization combined with the ideas of culture and identity where the subjects are viewed as part of an ancestral origin. The second approach considers that the dynamics produced by globalization need to be taken into account and also suggests that this approach makes it possible to demythologize the concepts in question. From this viewpoint it is possible to re-think outreach activities as a space for articulating multiple and diverse discourses. 


\section{LOS USOS DE LA CULTURA Y LA IDENTIDAD DESDE LA EXTENSIÓN UNIVERSITARIA EN ESTADOS UNIDOS}

La reflexión que deseo realizar tiene relación con los programas de extensión universitaria y los usos que ésta hace de los conceptos de cultura e identidad. La extensión universitaria es entendida como una de las principales funciones de la universidad, que tiene por misión conectar a la institución educativa con la sociedad. Ahora bien, la significatividad y relevancia de ella estarán dadas por la historia particular de la universidad, por la misión que se ha propuesto y por la sociedad específica en que está inserta. Desde esta perspectiva, la universidad es vista como la institución receptora de las necesidades formativas y culturales que la comunidad manifiesta y demanda. Se entiende, entonces, que la universidad no sólo es la institución que se interesa por responder a las demandas de la comunidad, sino que, además, debe anticiparse a todos aquellos requerimientos que la sociedad actual plantee. Esto último importa para el argumento que desarrollo en este ensayo: entender los programas de extensión dentro de una dinámica de cambio constante, que anticipa las necesidades de la comunidad asegurando, con esto, una conexión más significativa con los requerimientos de la sociedad. Para lograr este cometido, la consideración de los contextos en los que las comunidades y la universidad hacen estos planteamientos es particularmente relevante. Parte importante de la caracterización de los tiempos actuales está dada por los procesos de globalización y la forma en que, dentro de este paradigma, surgen nuevos y complejos cuestionamientos acerca del sujeto y la cultura, entre otros.

El argumento de este ensayo se sitúa en la lógica de que los significados y representaciones con las que trabaja la universidad, en cuanto a los conceptos de cultura e identidad, tienen un gran impacto 
en el tipo de apoyo y el significado atribuido a los programas de extensión por la comunidad beneficiada. En el contexto de la globalización, ha surgido un número importante de teorías sociales cuyo propósito ha sido el desmitificar antiguas formas de comprender los conceptos de cultura e identidad. Dentro de estas teorías se encuentran el posestructuralismo, el feminismo, el poscolonialismo y los estudios culturales, entre otros.

Si los programas de extensión son entendidos como el nexo entre la comunidad y la universidad, y si se piensa que ésta debiera anticipar los cambios experimentados en la comunidad, cuestionar estos conceptos de cultura e identidad parece relevante. Mi propósito específico es problematizar los usos de los conceptos de cultura e identidad que hace la extensión universitaria en Estados Unidos. Creo valioso discutir y cuestionar cómo la extensión universitaria se acerca a la comunidad y, más específicamente, cómo define a los grupos que atiende. En otras palabras, el hecho de complejizar la comprensión que se tiene de los grupos beneficiarios tiene una fuerte implicancia en el accionar de la universidad dentro del marco de los programas de extensión universitaria.

Las preguntas iluminadoras son: ¿De qué manera afectan los significados de cultura e identidad cuando se generan programas de ayuda y apoyo para comunidades minoritarias? ¿De qué manera estas concepciones y/o formas de comprender son modificadas en el tiempo y afectadas por procesos sociales e históricos? ¿De qué manera las definiciones de cultura e identidad afectan la misión de la extensión universitaria, si se hace desde el marco de la globalización?

En la primera parte presentaré la situación particular de la Universidad de Illinois en Estados Unidos, describiendo el trabajo llevado a cabo con comunidades minoritarias, aportando algunos datos específicos de composición de estos grupos y destacando información acerca de las condiciones, tanto históricas como sociales, de estas comunidades en Estados Unidos, específicamente el grupo de latinos. En segundo lugar, critico la perspectiva más orientada a tratar cultura e identidad como elementos estáticos y uniformes, en donde los sujetos pertenecientes al grupo beneficiario tienen un origen determinado $y$, a partir de esto, se genera toda una imagen estereotipada de su 
identidad. Finalmente, intento generar preguntas desde una mirada más cuestionadora de elementos culturales, a la vez que problematizar la forma en que la universidad debiera poner atención a elementos sociales que modifican o debieran modificar anquilosadas concepciones de quién es el sujeto y de la cultura que éste construye. Mi planteamiento, dentro de este último punto, es que, de esta manera, la universidad estaría en condiciones de cumplir la misión de la que hablé al principio: anticipar las necesidades de la comunidad y concretar sus objetivos de ayuda para ésta, en este caso, la minoritaria.

\section{Contexto}

La Universidad de Illinois es una institución pública que se destaca por su consolidado componente de investigación. Está catalogada dentro de las diez mejores universidades en Estados Unidos, en muchos de sus departamentos y facultades. Atiende a una población de, aproximadamente, 43.000 estudiantes, siendo la mayoría proveniente del mismo Estado (Illinois) en los programas de pregrado. Es importante comentar que el Estado de Illinois ha sido caracterizado como un Estado conservador desde el punto social y político.

Los programas de extensión de la Universidad de Illinois se desarrollan en aquellas áreas donde se han detectado necesidades, tanto en el área urbana como rural. Las acciones se extienden hacia jóvenes y adultos, familias, comunidades, negocios, industria y otras organizaciones. Específicamente, se ofrecen programas en cuatro grandes áreas: Desarrollo Juvenil, Agricultura y Recursos Naturales, Comunidad y Desarrollo Económico, y Familia y Ciencias del Consumidor. La comunidad, en general, es apoyada por el equipo de extensión en 79 unidades distribuidas alrededor de 101 condados en el Estado de Illinois. Existen educadores en catorce centros repartidos en todo el Estado, además de especialistas ubicados en el campus de la Universidad que participan en programas e investigación para estos servicios educativos y comunitarios.

En relación con los programas de asistencia a comunidades minoritarias, la universidad atiende a un número significativo de latinos, constituyendo éstos una población de 95.000 de un total de 1,6 millones de latinos en el Estado de Illinois, de los cuales la mayoría 
son mexicanos. Dentro de esta población total existen 500.000 jóvenes menores de 18 años, siete de cada nueve latinos se encuentran laboralmente activos y se espera que esta población crezca siete veces más rápido que las no latinas. Es así como se pronostica que, para el año 2030, existan 65 millones de latinos viviendo en Estados Unidos. Dentro de estas cifras, también se estima que cerca del 75\% de los latinos son nacidos en Estados Unidos y naturalizados como ciudadanos de ese país.

Debido a este creciente aumento de la población latina en Illinois, la extensión de la universidad está expandiendo sus recursos y compromisos con este grupo.

Paralelamente a este compromiso de la extensión universitaria, también existe, en el discurso oficial de la universidad, un reconocimiento explícito del valor que aportan a la comunidad universitaria estos grupos minoritarios, reconocimiento del valor de la diversidad en el contexto de la globalización, tal como lo establecen los numerosos pasajes de los documentos oficiales de la universidad.

“... dentro de las misiones de la Universidad está el reconocimiento de que su audiencia se expande por el mundo. Hoy el Estado (Illinois) prepara a sus estudiantes provenientes de diversos contextos para guiar este creciente mundo global. Su área de investigación examina el mundo de manera interrelacionada, en relación con temas críticos, y a la forma en que sus actividades públicas tienen consecuencias en el mundo entero"1.

Por otra parte, me parece importante destacar que la actividad de extensión universitaria debe ir acompañada de una dimensión complejizante de los conceptos de cultura e identidad dentro del marco de globalización. Procesos derivados de la globalización, tales como: la gran cantidad de gente moviéndose en el mundo, la explosión de las comunicaciones y la tecnología y la deterritorialización del sujeto, entre otros, sugieren una nueva construcción y pensamiento acerca de cultura e identidad.

1 Sitio web de la Universidad de Illinois, disponible en http://www.ilstu.edu/ 
Una concepción más homogénea de cultura e identidad

Entre Estados Unidos y México existe una extensa historia que se podría resumir en la dualidad colonizador-colonizado. Si nos remontamos hasta la conquista de los territorios mexicanos por parte de Estados Unidos, a mediados del siglo XIX, nos encontramos con que la modificación de las fronteras en la parte sudoeste de Estados Unidos genera también una modificación en la geografía humana y la posición social relativa de los habitantes de dichas tierras. Cuando México se independizó del Imperio Español, los vastos territorios al norte de Río Grande contaban con escasa población, lo que facilitó la llegada de colonos procedentes de Estados Unidos. Tras sucesivos conflictos, en 1846 Estados Unidos declara la guerra a México con el pretexto de cobrar viejas deudas. Luego de sucesivos combates, las tropas invasoras ocuparon México en 1847 y este país se vio obligado a aceptar una paz, calificada por muchos de humillante, que les hizo perder los territorios al norte de Río Grande, Texas, Nuevo México, Arizona, Nevada y California. Por otro lado, en el ámbito cultural, Estados Unidos reclama reconocimiento de la superioridad de su sistema social. El propósito de apelar a la historia es develar la idea implícita que surge cuando se dan relaciones de dominación y colonización entre países (el grupo dominante es cultural e intelectualmente superior al grupo conquistado), y aclarar cómo estas relaciones podrían perpetuarse en contextos sociales diferentes.

Relacionando la historia con los programas de extensión universitaria, me gustaría plantear las siguientes preguntas: ¿De qué manera la universidad puede reproducir esta situación de colonización en las relaciones con aquellos que son los beneficiarios de sus actividades, particularmente cuando estos son grupos minoritarios? ¿Cuál es la misión implícita de los programas de extensión universitaria? ¿Promover la fructífera regeneración de las culturas que atiende o actuar como colonizadores de minorías en nombre del bien concedido por la universidad?

El peligro que advierto es que si la actividad de extensión se organiza, formal e informalmente, en modos que fracturan las identidades culturales y étnicas de la comunidad, creando divisiones sociales, lingüísticas y culturales entre los miembros de la comunidad 
y con la sociedad dominante, se perpetúa una relación asimétrica de poder entre éstas.

El hecho de trabajar dentro de esta lógica supone una comprensión de cultura e identidad como conceptos homogéneos, estáticos y unitarios. En otras palabras, esto significa entender que las comunidades consisten en conjuntos demarcados y delimitados de formas y prácticas culturales específicas al grupo. Estas son definidas como tipos de propiedad final y son vistas como constitutivas de la capacidad de definición total del grupo, lo que lleva a pensar que son los miembros de un grupo los únicos totalmente competentes para entender el conocimiento y las experiencias pertinentes a este grupo en particular. Esta consideración conduce a menudo a la peligrosa tendencia de construir al "Otro" como aquellos que no son parte del grupo dominante o que no comparten un mismo ancestro, ya sea real o imaginario. El "Otro" en este contexto es, entonces, punto de exclusión. En consecuencia, el "Otro", su historia, su conocimiento y su cultura son percibidos como ilegítimos siendo, a menudo, omitidos. Planteo, por lo tanto, que existe una relación entre las concepciones implícitas de cultura e identidad, que subyacen a los programas de extensión universitaria, y los procesos de representación cultural. Estas formas preestablecidas de pensar a la gente, y que se materializan en leyes o programas de ayuda, actúan de tal manera que determinan y definen las identidades y culturas de los sujetos. El principal problema es que puede que estas leyes o programas se transformen en nacionalistas, racistas y/o discriminatorios en términos de género.

Por ejemplo, en el caso de la comunidad de latinos atendidos por los programas de extensión de la Universidad de Illinois, es importante destacar para la discusión el hecho de que el concepto de "inmigrante" implica una extensa y particular connotación histórica en la historia de Estados Unidos, país que ha sido en gran medida construido por continuas corrientes de inmigración. Esta historia provee a los individuos con identidades, con cualidades históricamente específicas, que son asumidas como de naturaleza universal. Las identidades impuestas por la noción de inmigrante limitan la experiencia de aquellos forzados a "usarlas" de manera incalculable. El categorizar a los sujetos dentro de un grupo específico, con características particulares, reproduce un supuesto modernista del sujeto y de su 
cultura, que impacta con los procesos más fragmentados de construcción de identidad llevados a cabo por los propios sujetos. Una vez en Estados Unidos, una serie de categorías de todo orden, como la racial, entre otras, es impuesta a los sujetos, afectando la percepción de quiénes son ellos y, como consecuencia, también sus experiencias. Consecuencias como las que se dan en el ámbito educativo, donde las minorías son generalmente catalogadas como "en desventaja" en comparación con la cultura dominante, podrían estar siendo asumidas y reforzadas en otros ámbitos educativos. Esta discusión acerca de cómo los grupos minoritarios son incorporados a la sociedad en Estados Unidos denota la aplicabilidad del modelo dominante de asimilación de las experiencias de grupos históricamente subordinados, como en el caso de la población latina.

Para profundizar más en el tema, es necesario destacar que, aparte del problema que se genera por el uso de esta idea monológica de identidad y cultura, también está el relacionado con las diferencias intragrupos y su significatividad en el contexto de los programas de ayuda ofrecidos por la extensión universitaria. En este caso podríamos hablar de distinciones que apuntan a las dimensiones de la identidad social de los sujetos, como lo son el género, la etnia, la religión, entre otras, y las innumerables intersecciones entre ellas. Estas distinciones tienen una gran repercusión en los contextos, lugares de trabajo y relaciones interpersonales que desarrollan estos grupos, forjando la idea de heterogeneidad dentro del mismo grupo de latinos. Por otro lado, hay que considerar el tema de las condiciones que les fuerzan a emigrar a Estados Unidos y cómo la proveniencia de un contexto de opresión económica y social los lleva a aceptar y tolerar sacrificios en un país desconocido. Todos estos elementos complejizan aún más la reflexión acerca de las diferencias intragrupo y el consecuente reconocimiento de la heterogeneidad a la que se enfrenta la extensión universitaria.

Aún es necesario incorporar otro elemento: las imágenes y representaciones de estas minorías que se encuentran en los medios son también importantes, porque, a menudo, no reflejan las verdaderas experiencias de estos grupos minoritarios; al contrario, las reducen, las comprimen y, por ello, las distorsionan. Cuando la cultura dominante categoriza a los sujetos como minorías, sus experiencias son reducidas a estereotipos poco representativos. Por esta realidad vale 
preguntarse: ¿De qué manera la extensión universitaria orienta sus definiciones de cultura e identidad de manera de no caer en esta visión más homogeneizante de los sujetos? Como es evidente, el peligro de adoptar un modelo etnocéntrico de cultura e identidad está en que la etiqueta de minoría impuesta a las personas sugiere patrones de comportamiento y racializa sus vidas teniendo consecuencias adversas de orden social y político.

A continuación quiero presentar una visión más acorde con los tiempos actuales y que responde de manera más crítica a los cuestionamientos homogeneizantes planteados anteriormente.

Una mirada alternativa: el triunfo de la multiplicidad

Como respuesta a esta concepción estática y unificada de entender cultura e identidad, se ha planteado, desde orientaciones más posmodernistas, que cultura e identidad son los productos de los encuentros entre las personas, de los inventarios de la apropiación intracultural y de los procesos de hibridación a los que el sujeto contemporáneo está expuesto. Desde esta postura se rechaza la idea de que cultura e identidad se entienda como la elaboración de la esencia ancestral de grupos en particular (Hall, 1996).

Desde este marco alternativo, cultura e identidad son conceptualizadas como inventarios de registro y asociación en movimiento entre estrechas fronteras de distinciones del grupo (Matus, y McCarthy, 2003). Desde aquí también se hace hincapié en los horizontes insospechados y se rescata el sinnúmero de afiliaciones entre grupos humanos y culturas, normalmente entendidas como distintivas. Lo rescatable y aplicable para discutir dentro del marco de la extensión universitaria es que el trabajo de estas posturas posmodernistas invita a recrear un mayor inventario de asociaciones en la conceptualización de cultura e identidad. Este tratamiento más complejo y relacional debiera subyacer a las conceptualizaciones manejadas por la extensión de la universidad, porque promueve reflexionar sobre algunos supuestos.

Primero, se hace necesario repensar por qué el supuesto de una oposición entre los cánones del "mundo industrializado" y las formas 
culturales del "resto del mundo" es ilegítimo. De acuerdo a estas posturas posmodernas, específicamente desde el poscolonialismo, se sugiere que esta oposición no se sustenta en datos empíricos. De ser así, y adecuando este supuesto al contexto de la presente discusión, las actividades de extensión debieran tener una visión más fragmentada de los grupos que atiende.

Segundo, se sugiere que el contexto contemporáneo de las experiencias está profundamente afectado por la globalización y el siempre expansivo patrón de integración de las realidades dinámicas globales: se piensa que hoy el mundo es más interdependiente. Desde esta premisa, y pensando cómo afectaría a los programas de extensión, podría pensarse en la producción de conocimiento y en cómo éste es entendido y recibido por los grupos minoritarios. El conocimiento no es un proceso singular ni lineal; al contrario, se entiende mejor cuando es facilitado por una práctica abierta con raíces en la pluralidad de puntos de vista, visiones de mundo y sujetos que representan cada una de estas diversidades.

En tercer término, el reconocimiento del contexto internacional es un factor decisivo en la problematización de los procesos culturales y de subjetivización. En el mundo interconectado de hoy, muchos investigadores han llegado a entender el concepto de identidad como una herramienta analítica primordial para entender la sociedad y sus instituciones. Dramáticos cambios en el ámbito internacional, que van desde la constitución de las corporaciones transnacionales y la competencia global, la innovación y alcance masivo de la tecnología computacional y de comunicaciones, el terrorismo internacional, y la noción de que los individuos son deterritorializados (es decir, que ya no están necesariamente ligados a un lugar, cultura y/o lenguaje específico), traen una serie de temas complejos acerca de las nociones de cultura e identidad.

Desde esta perspectiva alternativa hay un énfasis claro en problematizar las intersecciones de las diferentes dimensiones de la identidad en la construcción del sujeto y, por ende, de la cultura. Se argumenta que, dependiendo de dónde el sujeto esté socialmente situado, tiene acceso a conocer ciertas cosas y no otras. Esto no es sólo un tema de acceso, sino también de perspectiva, proveyendo a 
los sujetos de posiciones y recursos específicos. En esta lógica, la precaución que hay que tener es que las actividades de extensión no se transformen en mecanismos para construir sujetos y producir relaciones de poder. Invocar la cultura e identidad como sustancias originales se hace cómplice con la naturalización de las estructuras de poder que operan en la creación y mantención de ellas. En el caso de la extensión universitaria, éstas podrían tomar el estatus de construcciones normalizadoras que configuran los mundos sociales en los que los sujetos viven y, como consecuencia, se convierten en una forma de producción cultural. Por esto he planteado como objetivo de este artículo el problematizar estos conceptos que parecen inocentes en el contexto de la extensión universitaria. Ésta debe complejizar el alcance de sus actividades con la comunidad; en caso contrario, se estará trabajando con una perspectiva incompleta y limitada de cultura e identidad.

Ya al final de mi reflexión, quiero resaltar algunas de las ideas que he venido forjando en estas páginas. Me parece de singular importancia observar las formas en las cuales el contexto global afecta las acciones de las instituciones y sus relaciones con la comunidad, ya que, en un mundo donde hay un incremento de la interdependencia y competición, estos factores internacionales no pueden quedar fuera del análisis, particularmente en el caso de las universidades, afectadas por procesos que tienden a focalizarse en estrategias siempre ligadas al reconocimiento de la diversidad como una de las mayores fortalezas para responder al paradigma de la globalización.

Dentro del presente contexto de globalización, los conceptos de cultura e identidad no pueden ser concebidos como fijos, establecidos y llenos de elementos específicos. Al contrario, cultura e identidad son construcciones discursivas e históricas, por lo tanto, están en un continuo proceso de cambio. Insisto en que hay imágenes que forman parte integral de la idea de sujeto que deben ser interrumpidas. Estas imágenes crean contextos dañinos, relaciones no deseadas y contextos viciosos que pueden llegar a perpetuar una estructura de poder sobre los grupos minoritarios. El problema es que sobre la base de estas imágenes se define lo que es beneficioso para cierto grupo, vulnerando las vidas, historias, deseos e imágenes de las personas. Para éstos sería beneficioso entender que la cultura e identidad son siempre un "lugar 
de dificultad" (Hall, 1996, p. 7). Si existe el reconocimiento de que cultura e identidad son el resultado de encuentros dinámicos entre las personas, y de experiencias e historias, sería interesante pensar que la extensión universitaria pueda constituir un espacio de articulación de estas narrativas. 


\section{REFERENCIAS BiBLIOGRÁFICAS}

Alcoff, Linda, "The Problem of Speaking for Others", en Cultural Critique, Winter 91-92, 1991, pp. 5-32.

Alcoff, Linda, "Introduction: Identities: Modern and Postmodern", en Martin Alcoff, Linda \& Mendieta, Eduardo (eds.), Identities: Race, Class, Gender, and Nationality, Editorial Blackwell Publishing Ltd., Massachusetts, 2003, pp. 1-8.

Appadurai, Arjun, Modernity at Large. Cultural Dimensions of Globalisation, The University Minnesota Press, Minneapolis, 1996.

Beck, U., "What is Globalisation?", in Held, David \& McGrew, Anthony (eds.), The Global Transformation Reader. An Introduction to the Globalisation Debate, Polity Press, Cambridge, pp. 99-104.

Castells, Manuel, The Power of Identity, Blackwell Publishers Inc., Massachusetts, 1997, pp. 34-53.

Clifford, James, Routes. Travel and Translation in the Late Twentieth Century, Harvard University Press, Cambridge, 1997.

Flores, J., "The Latino Imaginary: Meanings of Community and Identity", en Martin Alcoff, Linda \& Mendieta, Eduardo (eds.), Identities: Race, Class, Gender, and Nationality, Editorial Blackwell Publishing Ltd., Massachusetts, 2003, pp. 96-104.

Hall, Stuart, "Who Needs 'Identity'?", en Hall, Stuart \& Gay, Paul du, Questions of Cultural Identity, Sage, London, 1996, pp. 1-17.

Hall, Stuart, "New Ethnicities", en Martin Alcoff, Linda \& Mendieta, Eduardo (eds.), Identities: Race, Class, Gender, and Nationality, Editorial Blackwell Publishing Ltd., Massachusetts, 2003, pp.90-95

Kaplan, Catherine, Questions of Travel, Duke University Press, Durham, 2000 .

Matus, Claudia \& McCarthy, Cameron, "The Triumph of Multiplicity and the Carnival of Difference", en Pinar, William, Curriculum Dilemmas in the Age of Postocolonialism \& Globalization, Lawrence Erlbaum Ass., New Jersey, 2003. 